\title{
Does Emotional Expressivity Predict Somatization?
}

\section{Hossein Kaviani}

School of Psychology, University of Bedfordshire, Luton, LU1 3JU, UK

*Corresponding author: Hossein Kaviani, School of Psychology, University of Bedfordshire, Luton, LU1 3JU, UK, Tel: +44-1582743765; E-mail: hossein.kaviani@beds.ac.uk

Received date: January 05, 2018; Accepted date: January 13, 2018; Published date: January 21, 2018

Copyright: $\odot 2018$ Kaviani $\mathrm{H}$. This is an open-access article distributed under the terms of the Creative Commons Attribution License; which permits unrestricted use; distribution; and reproduction in any medium; provided the original author and source are credited.

Citation: Kaviani H (2018) Does Emotional Expressivity Predict Somatization? . Clin Depress 4: e106. doi:10.4172/2572-0791.1000e106

Keywords: Somatization; Expressivity; Culture

\section{Editorial}

Somatization is a massive clinical challenge in the primary health care system, as sometimes it becomes extremely difficult for clinicians to differentiate between somatization syndrome and other actual physical conditions. This creates a situation in which misdiagnosis and mal-practice, probably resulting in adverse consequences would be inevitable. This phenomenon can be observed in people with diverse cultural background with the prevalence varying from 3\% to 35\% of patients in primary health care system [1-6]. Based on the evidence provided by these studies, somatisation proved to be common in different ethnic groups, but the prevalence rates differ, though the evidence for its correlates do not seem to be consistent. It is pointed out that people with Eastern cultural backgrounds, instead of using psychological terms, are more likely to express their emotional pains through somatic symptoms [7,8]. There are studies that show a significantly positive relationship between introversion (defined by traits like being 'reserved', 'introspective' and 'less talkative and sociable') and somatization symptoms [9].

Moreover, evidence confirms the impact of emotional expressiveness on somatization and emotional [10]. That is, when people in a cultural context feel comfortable to express and share what they think and how they feel, they would be less likely to somatise their psychological and emotional problems; people living in a suppressive cultural context would be more likely to do so [11-13]. This might even be reflected in language and terms people use to communicate in a society. With this assumption in mind, Kaviani et al. [14] scrutinized Persian vocabulary and found out that Iranians tend to use more bodyrelated words while expressing their emotional states. This appears to be in agreement with above argument. This would imply that practitioners should be aware of cultural and linguistic context in which the patients present their symptoms.

Kaviani et al. [15] investigated the link between emotional expressivity and symptom presentation among depressed patients in a primary care setting. They found higher levels of somatization among Hispanic patients compared with their White American counterparts. In this study, female participants turned out to be higher on somatization than their male counterparts. This supports further the potential link between emotional expressivity and the likelihood of expressing bodily pains and complains.

In keeping with the initial point made in this note, practitioners in primary health care system would gain insight and knowledge around the linkage between emotional expressivity and tendency to somatise among people with different cultural background which, in turn, would help them to avoid misdiagnosis and consequently mal-practice. Besides, the role of emotional expressivity in somatising might imply a possible therapeutic ramification. That is, one can assume that working on improvement of patient's expressivity would potentially lead to a decremental impact on their tendency to somatise. Although this assumption is supported by some evidence, it still needs to be put into further empirical test [10].

\section{References}

1. Busch FN (2014) Clinical approaches to somatization. J Clin Psychol 70: 419-427.

2. Kirmayer LJ, Robbins JM (1991) Three forms of somatization in primary care: prevalence, co-occurrence, and sociodemographic characteristics. J Nerv Ment Dis 179: 647-655.

3. Maany FH (1981) Treatment of depression associated with Briquet's syndrome. Am J Psychiatry 138: 373-376.

4. Escobar JI, Gara M, Silver RC, Waitzkin H, Holman A, et al. (1998) Somatisation disorder in primary care. Br J Psychiatry 173: 262-266.

5. Gureje O, Simon GE, Ustun TB, Goldberg DP (1997) Somatization in cross-cultural perspective: A World Health Organization Study in Primary Care. Am J Psychiatry 154: 989-995.

6. Peveler R, Kilkenny L, Kinmonth A (1997) Medically unexplained physical symptoms in primary care: A comparison of self-report screening questionnaires and clinical opinion. J Psychosom Res 42: 245-252.

7. Farooq S, Gahir MS, Okyere E, A.J, Oyebode F (1995) Somatization: A transcultural study. J Psychosom Res 39: 883-888.

8. Ryder GA, Yang J, Zhu X, Yao S, Yi J, et al. (2008) The cultural shaping of depression: Somatic symptoms in China, psychological symptoms in North America? J Abnorm Psychol 117: 300-313.

9. Hyphantis T, Goulia P, Carvalho AF (2013) Personality traits, defence mechanisms and hostility features associated with somatic symptom severity in both health and disease. J Psychosom Res 75: 362-369.

10. Kim S, Ki J (2014) A case study on the effects of the creative art therapy with stretching and walking meditation - Focusing on the improvement of emotional expression and alleviation of somatisation symptoms in a neurasthenic adolescent. The Arts in Psychotherapy 41: 71-78.

11. King LA, Emmons RA (1991) Psychological, physical and interpersonal correlates of emotional expressiveness, conflict and control. European Journal of Personality 5: 131-150.

12. Kleinman A, Kleinman J (1985) Somatization, interconnections among cultures, depressive experiences, and meaning of pain: A study in Chinese society. In: Kleinman A, Kleinman J, Good B (eds.). Culture and Depression Berkeley. University of California Press. pp: 132-167.

13. Pennebaker JW (1995) Emotion, disclosure, and health. American Psychological Association, Washington, DC.

14. Kaviani H, Pournaseh M, Sagan O (2015) "Emotion-related words" in Persian dictionaries: Culture, meaning and emotion theory. International Journal of Linguistics, Literature and Culture 2: 1-12.

15. Kaviani H Tabrizi MC (2016) Emotional expressivity and somatization symptoms in clinically depressed patients. Clin Depress 3: 113. 